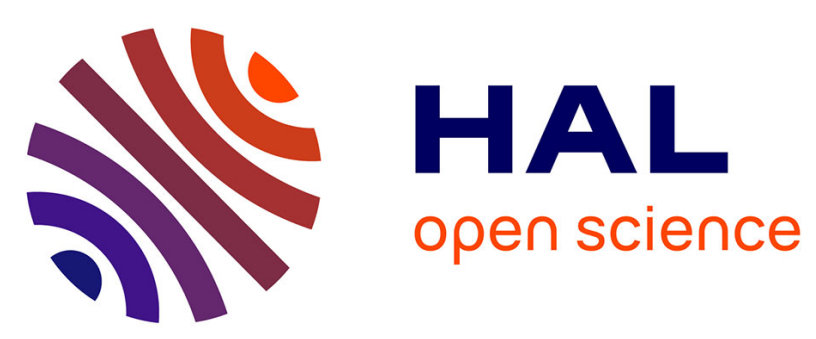

\title{
Organocatalytic vs. Ru-based electrochemical hydrogenation of nitrobenzene in competition with the hydrogen evolution reaction
}

\author{
Alicia Moya, Jordi Creus, Nuria Romero, José Alemán, Xavier \\ Solans-Monfort, Karine Philippot, Jordi García-Antón, Xavier Sala, Rubén \\ Mas-Ballesté
}

\section{To cite this version:}

Alicia Moya, Jordi Creus, Nuria Romero, José Alemán, Xavier Solans-Monfort, et al.. Organocatalytic vs. Ru-based electrochemical hydrogenation of nitrobenzene in competition with the hydrogen evolution reaction. Dalton Transactions, 2020, 49 (19), pp.6446-6456. 10.1039/D0DT01075H . hal02612766

\section{HAL Id: hal-02612766 \\ https://hal.science/hal-02612766}

Submitted on 9 Dec 2020

HAL is a multi-disciplinary open access archive for the deposit and dissemination of scientific research documents, whether they are published or not. The documents may come from teaching and research institutions in France or abroad, or from public or private research centers.
L'archive ouverte pluridisciplinaire HAL, est destinée au dépôt et à la diffusion de documents scientifiques de niveau recherche, publiés ou non, émanant des établissements d'enseignement et de recherche français ou étrangers, des laboratoires publics ou privés. 


\section{ARTICLE}

\section{Organocatalytic vs Ru-based Electrochemical Hydrogenation of Nitrobenzene in Competition with Hydrogen Evolution Reaction}

Received 00th January 20xx, Accepted 00th January 20xx DOI: $10.1039 / \times 0 \times x 00000 x$

\author{
Alicia Moya, ${ }^{a}$ Jordi Creus, ${ }^{\mathrm{b}, \mathrm{c}}$ Nuria Romero, ${ }^{\mathrm{b}}$ José Alemán, ${ }^{\mathrm{d}, \mathrm{e}}$ Xavier Solans-Monfort, ${ }^{\mathrm{b}}$ Karine \\ Philippot, ${ }^{c}$ Jordi García-Antón, ${ }^{b}$ Xavier Sala, ${ }^{* b}$ and Rubén Mas-Ballesté*a,e
}

Oxidized carbon fibres and ruthenium nanoparticles supported on unmodified carbon fibres have been studied for electrocatalytic $\mathrm{PhNO}_{2}$ hydrogenation. While similar reaction outputs have been observed for both catalytic systems, DFT calculations revealed some significant differences on the reaction pathways related to distinct interactions of the catalytic materials with substrates or products. Furthermore, although $\mathrm{PhNO}_{2}$ hydrogenation is the favoured reaction, HER competes in both systems under the catalytic conditions.

\section{Introduction}

Electrochemical reduction of organic substrates is not only an important synthetic method but also, an efficient way to remove persistent pollutants ${ }^{1-3}$ and to produce energy vectors based on reversible hydrogenation/dehydrogenation processes. ${ }^{4-6}$ Such processes, when carried out in the presence of proton sources, require electrocatalysts able to hydrogenate organic functionalities. ${ }^{7}$ Such electrocatalytic materials are intended to increase both the activity and selectivity of the reduction reaction. Regarding the selectivity, the occurrence of Hydrogen Evolution Reaction (HER) as a parasite process in competition with the hydrogenation of organic reagents is ubiquitously observed. ${ }^{8}$ The characteristics of the electrocatalytic materials are expected to determine the reaction output, tipping the balance in favour of one or another process. The rational design of materials able to electrocatalytically hydrogenate organic substrates or efficiently mediate HER requires a deep understanding of the mechanisms underlaying both pathways. Regarding the mechanism of HER, it has been studied by using a wide range of materials due to the need of clean and renewable alternatives to the use of fossil fuels. ${ }^{9-11}$ Pt-based catalysts are known to be highly performant for HER, but due to economic concerns, its substitution by catalytic materials based on cheaper and earthabundant elements is necessary. ${ }^{12-15}$ Metal-free catalysts, such

a. Department of Inorganic Chemistry (module 07). Universidad Autónoma de Madrid, 28049, Madrid, Spain.E-mail: ruben.mas@uam.es

b. Departament of Chemistry. Universitat Autònoma de Barcelona, 08193, Cerdanyola del Vallès, Barcelona, Spain.E-mail: Xavier.sala@uab.cat

c. CNRS, LCC (Laboratoire de Chimie de Coordination), UPR8241, Université de Toulouse, UPS, INPT, F-31077 Toulouse cedex 4, France.

d. Department of Organic Chemistry (module 01). Universidad Autónoma de Madrid, 28049, Madrid, Spain.

e. Institute for Advanced Research in Chemical Sciences (IAdChem), Universidad

Autónoma de Madrid, 28049, Madrid, Spain.

† Electronic Supplementary Information (ESI) available. See

DOI: $10.1039 / \mathrm{x} 0 \times x \times 0000 \mathrm{x}$ as carbon-based materials ${ }^{16,17}$ as well as Ru-based catalysts ${ }^{18-20}$ seem to be ideal alternatives for this purpose.

In a recent report, we applied carbon microfibres (CFs) prepared by the pyrolysis of polyacrylonitrile (PAN) as an alternative electro-organocatalytic material for HER (Fig. 1a, top). ${ }^{21}$ Carbon fibres have a graphene-like structure including pyridyl moieties. This carbon-based material can be easily oxidized to generate carboxylic acid groups at the surface, constituting nicotinic fragments in the carbon fibre structure. The resulting material that will be further referred as ox-CF presents HER electrocatalytic activity. Indeed, ox-CF can act as catalytic centres for the HER in way similar to those of NADPH in biological systems ${ }^{22,23}$ and Hantzsch esters in synthetic reduction procedures. ${ }^{24-26}$ In another work, we used pristine CFs as support for Ru-NPs in order to achieve stable and high surface area functionalized electrodes (Fig. 1a, bottom). ${ }^{27}$ Our results demonstrated the viability of such hybrid materials composed by Ru-NPs onto CF as remarkable electrocatalysts for the HER (referred as Ru-CF). A common feature of both systems (ox-CF and Ru-CF) is the generation of hydride species that can be protonated to form molecular hydrogen. Also, they can hydrogenate a variety of substrates, widening the applicability of electrochemical systems usually employed for HER. Furthermore, electrocatalytic procedures are convenient strategies, avoiding the manipulation of $\mathrm{H}_{2}$ gas or metal hydride derivatives $\left(\mathrm{LiAlH}_{4}\right.$ or $\left.\mathrm{NaBH}_{4}\right)$, commonly used in chemical hydrogenation processes.

In this work, we compared the electrocatalytic HER and the hydrogenation of a model substrate, namely nitrobenzene $\left(\mathrm{PhNO}_{2}\right)$, using as electrocatalysts functionalized carbon fibres (ox-CF and Ru-CF) (see Fig. 1b). The reduction of $\mathrm{PhNO}_{2}$ is of great interest since nitro aromatic compounds (such as explosives, dyes, agrochemicals or pesticides) are common water contaminants. ${ }^{28,29}$ Although many alternatives have been explored, ${ }^{30-35}$ electrochemical procedures are still the most convenient ways to reduce $\mathrm{PhNO}_{2}$ and thus potentially degrade pollutants containing this fragment. However, in the presence 
a) Previous work: Carbon Fiber-based Electrocatalyst for HER



b) This work: Electrocatalytic $\mathrm{HER}$ vs $\mathrm{PhNO}_{2}$ Reduction
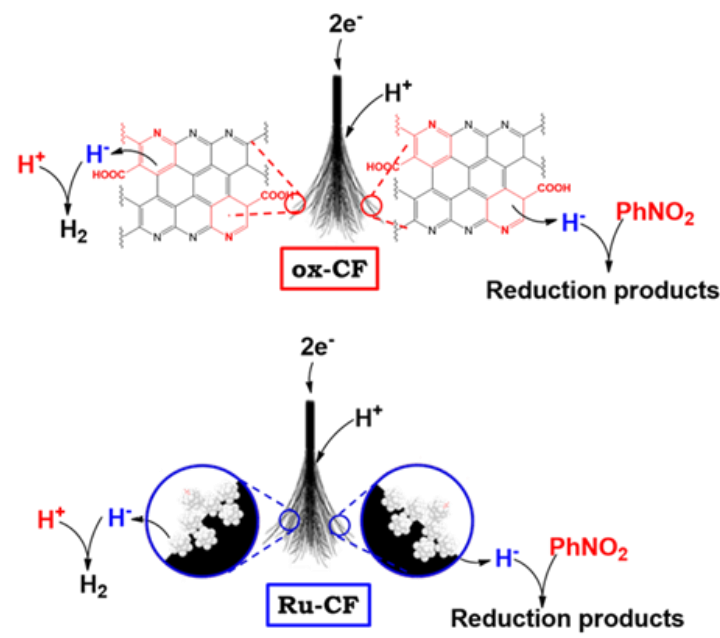

Fig. 1 Schematic representation of a) Carbon Fibre-based electrocatalysts for HER (previous work) ${ }^{21,27}$ and b) $\mathrm{HER}$ vs hydrogenation of $\mathrm{PhNO}_{2}$ using same electrocatalysts (this work)

of protic media this process would typically be in competition with HER. Indeed, electrochemical reduction of nitrobenzene is often performed using a platinum electrode which is also a typical electrocatalyst for HER. ${ }^{36-38}$ Currently, electrodes used for the electroreduction of aromatics are based on noble metals, which limit their applicability for large scale processes given their its high cost and low abundance. ${ }^{39}$ Thus, there is a need to find efficient, inexpensive, easy to make and recyclable electrocatalytic materials with no noble metals 40,41 for the reduction of nitroaryl compounds. This reaction will be deeply presented in this manuscript, considering HER as a competitive process. We will determine the intrinsic properties of ox-CF and $\mathrm{Ru}-\mathrm{CF}$ as electrocatalysts for both reactions (compare Fig. 1b top and bottom) by means of combination of experimental and theoretical results. This work will add fundamental understandings on the distinctive catalytic behaviour of metalbased and metal-free electrocatalysts. The obtained fundamental insights may allow the future design of active and selective electrocatalytic materials for HER or hydrogenation of organic substrates.

\section{Results and discussion}

\section{Experimental Results}

Details on synthesis and characterization of the electrocatalytic materials used in this comparative study are reported elsewhere.21,27 Previous mechanistic studies revealed that both, ox-CF and Ru-CF, generate hydrides, that after protonation, lead to HER. Then, the question is to determine if these systems are capable to transfer the hydride to nitrobenzene. Although the productivity typically formed from this process is simply aniline, several other species can be generated. Therefore, as previously reported, a more complex mechanism should be considered for hydrogenation of nitrobenzene (see Fig. 2). ${ }^{42}$

The electrochemical behaviour of nitrobenzene has been analysed by cyclic voltammetry (Fig. S1). A reduction signal is observed at $E_{1 / 2}=-1.1 \mathrm{~V}$ vs $\mathrm{Ag} / \mathrm{AgCl}$, which is associated to a reversible electron transfer process. According to this result, -1 $V$ vs $\mathrm{Ag} / \mathrm{AgCl}$ has been chosen as the limit potential for all electrochemical experiments in order to achieve electrocatalytic hydrogenation and avoid electrochemical electron transfer. The choice of an adequate proton source is determinant for the efficiency of the reaction. Also, in order to understand such effect, some factors have to be considered: 1 ) Electrocatalytic hydrogenation of nitrobenzene will compete with HER and 2) Hydride regeneration on the catalytic centres involves injection of two electrons into the electrocatalytic material and further protonation. Combination of both factors will determine the effect of the proton source in the output of the electrocatalytic $\mathrm{PhNO}_{2}$ hydrogenation. In order to optimize the composition of our system we compared linear sweep voltammetry results of ox-CF and Ru-CF using water ( $1 \mathrm{M})$, trifluoroacetic acid (TFA, $20 \mathrm{mM}$ ) and a mixture of both as proton sources (Fig. S2) in acetonitrile. Maximized electrochemical response is observed for both catalytic systems when a mixture of water and TFA is used. Fig. 3 presents the linear sweep voltammetries recorded in the absence (top) and in the presence (bottom) of nitrobenzene at a scan rate of 10 $\mathrm{mV} / \mathrm{s}$. Measurements were performed in acetonitrile using $\mathrm{NaClO}_{4}(0.2 \mathrm{M})$ and TFA $(20 \mathrm{mM})$ and water $(1 \mathrm{M})$ mixture.
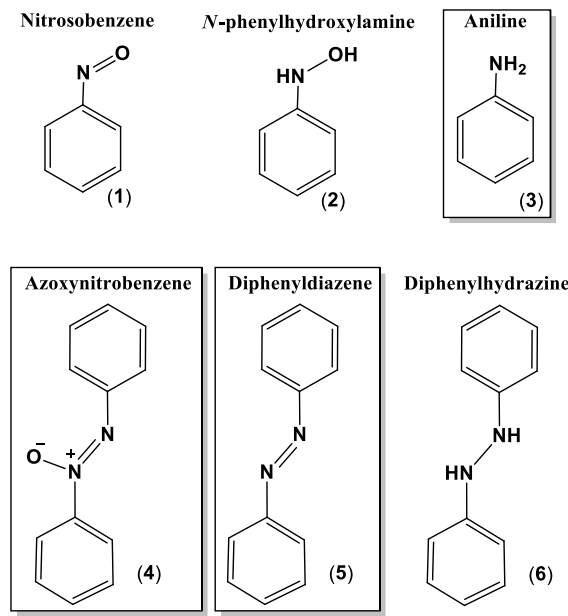

Fig. 2 Possible species that can be generated from hydrogenation of nitrobenzene with species detected in this work highlighted inside the frames. 


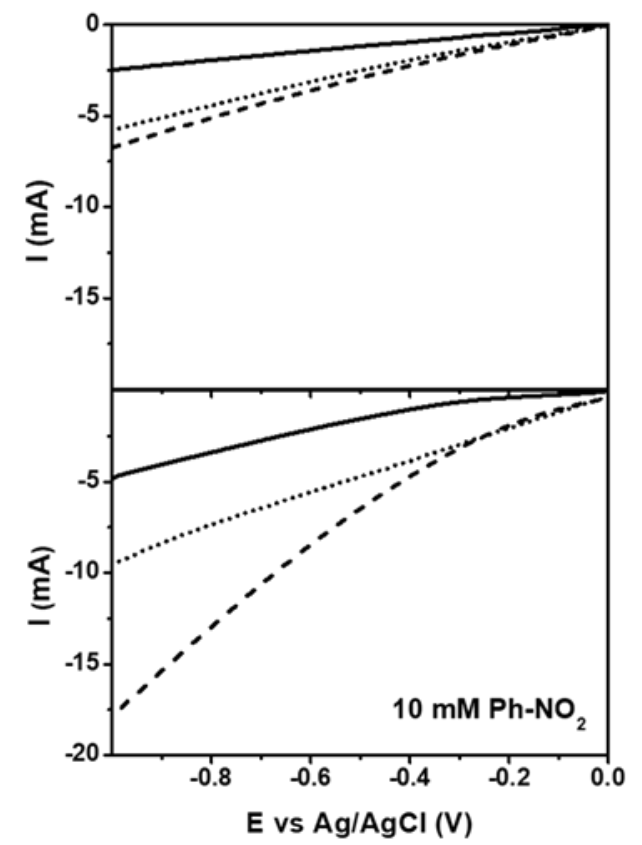

Fig. 3 Linear sweep voltammetries measured using pristine (solid line), oxidized (dashed line) and Ru-based (dotted line) carbon fibre electrodes in the absence (top) and in the presence (bottom) of $10 \mathrm{mM}$ of nitrobenzene. In all cases, solvent is acetonitrile containing $\mathrm{H}_{2} \mathrm{O}(1 \mathrm{M})$, TFA (20 mM) and $\mathrm{NaClO}_{4}(0.2 \mathrm{M})$.

The current intensity values at $-1 \mathrm{~V} v s \mathrm{Ag} / \mathrm{AgCl}$ are presented in Table 1 for comparison purpose. Electrochemical responses of the two materials studied (ox-CF and Ru-CF) are much higher than that of the pristine fibre (CF), which demonstrates their catalytic properties, either for the proton reduction or for the nitrobenzene hydrogenation (see -2.48 vs -6.76 and -5.77 $\mathrm{mA} ;-4.85$ vs -17.89 and $-9.31 \mathrm{~mA}$ ). Current intensity is greatly enhanced upon addition of $\mathrm{PhNO}_{2}$ when using ox-CF (see -6.76 vs $-17.89 \mathrm{~mA}$ ). However, such an effect is less pronounced for the Ru-based electrocatalyst (see -5.77 vs $-9.31 \mathrm{~mA}$ ). $\mathrm{PhNO}_{2}$ hydrogenation is clearly facilitated with the purely organic electrocatalyst while whit the RU.CF inorganic catalyst, HER seems to compete more with the nitrobenzene hydrogenation.

Then, a $5 \mathrm{~h}$ electrolysis has been performed at a constant potential of $-1 \mathrm{~V} v s \mathrm{Ag} / \mathrm{AgCl}$ for the two electrocatalysts in the presence of water and TFA mixture (Fig. S3). The reaction outputs have been analysed by gas chromatography (GC). Interestingly, higher conversion was found for oxidized carbon fibres (Fig. 4a), as expected from the current observed in the LSV. It is important to note that the concentration of active sites is hard to determine. However, the activity observed cannot be uniquely related to the intrinsic properties of the active sites but also to their relative concentration on the electrode surface.

Table 1 Current intensities at $-1 \mathrm{~V}$ vs $\mathrm{Ag} / \mathrm{AgCl}$ in $1 \mathrm{M} \mathrm{H}_{2} \mathrm{O}+20 \mathrm{mM}$ TGA corresponding to the linear sweep voltammetries of Fig. 3.

\begin{tabular}{cccc}
\hline $\begin{array}{c}\left.\mathrm{PhNO}_{2}\right] \\
(\mathrm{mM})\end{array}$ & $\begin{array}{c}\text { I of } \mathrm{CF} \\
(\mathrm{mA})\end{array}$ & $\begin{array}{c}\text { I of ox-CF } \\
(\mathrm{mA})\end{array}$ & $\begin{array}{c}\text { I of } \mathrm{Ru}-\mathrm{CF} \\
(\mathrm{mA})\end{array}$ \\
\hline 0 & -2.48 & -6.76 & -5.77 \\
10 & -4.85 & -17.89 & -9.31 \\
\hline
\end{tabular}

a)

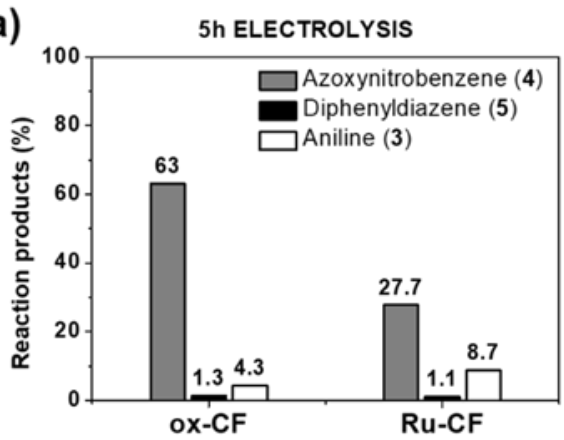

b)

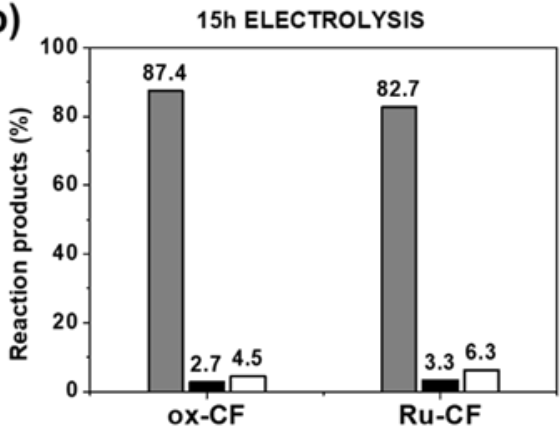

Fig. 4 Reaction products of the electrocatalytic reduction of nitrobenzene at $-1 \mathrm{~V}$ vs $\mathrm{Ag} / \mathrm{AgCl}$ after a) $5 \mathrm{~h}$ and b) $15 \mathrm{~h}$ of reaction using ox-CF and Ru-CF as electrodes in a mixed solution of $1 \mathrm{M}$ of water and $20 \mathrm{mM}$ of TFA in $\mathrm{NaClO}_{4}(0.2 \mathrm{M}$, acetonitrile).

Furthermore, we investigated the reaction output after a longer reaction time ( 5 vs $15 \mathrm{~h}$, Fig. $4 \mathrm{a}$ and $4 \mathrm{~b}$ ). After $15 \mathrm{~h}$, the consumption of nitrobenzene is almost complete for both electrocatalytic materials. The pristine carbon fibre electrode was also tested for $5 \mathrm{~h}$. In these conditions, no significant amounts of products were found, corroborating that the catalytic behaviour observed with the two other materials results from either the oxidation of carbon fibres or the presence of Ru-NPs (Fig. S3).

As shown on Fig. 4 and S4, the major product of the nitrobenzene reduction after bulk electrolysis at $-1 \mathrm{~V}$ during 5 and $15 \mathrm{~h}$, is in all cases azoxynitrobenzene dimeric species (4). In addition, residual amounts of aniline (3) and diphenyldiazene (5) have been observed. Interestingly, amounts of aniline (3) at $15 \mathrm{~h}$ are equal or even lower than those detected at $5 \mathrm{~h}$. In contrast, as observed for the major product (4), amounts of the minor product diazobenzene (5) are significantly superior at 15 $\mathrm{h}$ than at $5 \mathrm{~h}$. These observations indicate that, a) the generation of aniline (3) corresponds to short reaction times, b) the formation of dimeric species (4 and 5 ) requires accumulation of monomeric intermediates that are produced over the electrochemical process, thus requiring longer reaction times. Remarkably, although the nature of the two catalytic systems studied is very distinct, similar product compositions are observed. However, faradaic yields after $15 \mathrm{~h}$ electrolysis are approximately $75 \%$ for ox-CF and $65 \%$ for Ru-CF, thus indicating that HER is a minor process but is more significant for Ru-CF, in agreement with voltammetry data (see Fig. 3). 


\section{Theoretical Calculations}

Methodological Strategies. In order to get a deep understanding of the processes occurring in the electrocatalysis, we performed a computational DFT study. Two sets of calculations were carried out. The full catalytic process involving the organocatalytic system (ox-CF) was represented with a molecular model from a previous work. ${ }^{21}$ The hybrid M062X functional ${ }^{43}$ was used and atoms were represented with the $6-311 G^{* *}$ basis sets ${ }^{44}$ including solvation effects of acetonitrile $(\varepsilon=37.5)$ by means of solvation model density (SMD). ${ }^{45}$. The protonation steps of the $\mathrm{PhNO}_{2}$ hydrogenation were studied also at this level of theory without including any of the two catalysts in the calculations. The reactivity of Ru-NPs was studied with VASP.46,47 For saving computational time, the exploration was limited to the thermodynamics of all steps and the transition states that appeared to be key for the organocatalytic system. VASP includes periodic boundary conditions and defines the basis with plane wave. Thus, interaction with neighbour images was avoided by using a $25 \AA$ edge cubic unit cell. These calculations were performed with the PBE GGA functional ${ }^{48}$ and an energy cut-off of $500 \mathrm{eV}$ Dispersion forces were taken into account with Grimme D2 empirical correction ${ }^{49}$ (see Computational Details section for further information). Remarkably, values for the Ru-NPs do not include thermal corrections. However, since all steps are unimolecular, $\Delta \mathrm{E}$ and $\Delta \mathrm{G}$ values are expected to show little variations. In any case, it is worth to note that since the methodologies used for modelling the two catalytic processes differ significantly, comparison should be done with caution, particularly for the case of the energy barriers as it is wellknown that PBE tends to underestimate them. ${ }^{50}$

Initial Considerations. As reported previously, ${ }^{21}$ the electroorganocatalytic behaviour of oxidized carbon fibres is initiated by the injection of two electrons on the carbon material that contains randomly distributed nicotinic fragments. It is known that the value for the work function of highly orientated pyrolytic graphite (HOPG) in air is c.a. $4.8 \mathrm{eV},{ }^{51}$ which is expected to be close to that of the carbon fibre material. Thus, it should allow stabilization of injected electrons through the graphitic $\pi$ electron density. However, considering the reduced size of the molecular model used in our calculations to simulate the graphenic region, the stabilization energy after injection of two electrons $(3.13 \mathrm{eV})$ is underestimated. After injection of two electrons model, the negative charge increases the basicity of the pyridinic nitrogen atom resulting in its barrierless protonation. Thus, we considered as the starting point the negatively charged species shown in Scheme 1 (centre) that contains a protonated pyridinic nitrogen atom. Further

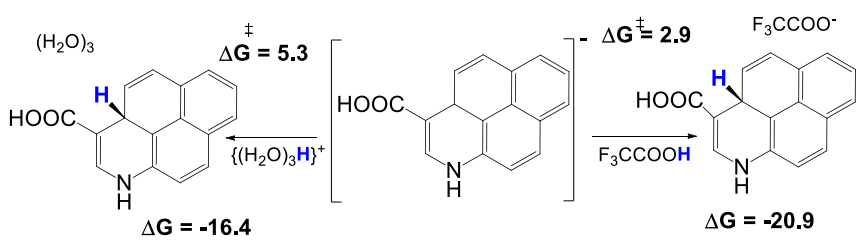

Scheme 1 Generation of the species able to transfer hydrides in the ox-CF organocatalytic system (energy values are given in $\mathrm{kcal} \mathrm{mol}^{-1}$ ).

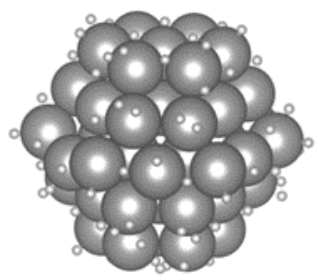

Fig. $5 \mathrm{Ru}_{57} \mathrm{H}_{88}$ model used for representing the Ru-NPs.

evolution of this reduced species consists in its protonation in the para-position with respect to the nitrogen atom.

The corresponding species can transfer the hydride that is responsible for the observed reactivity. Taking into account the nature of the reaction medium, we considered two possible protonation agents: TFA molecule and hydrated proton $\left[\mathrm{H}_{3} \mathrm{O}\left(\mathrm{H}_{2} \mathrm{O}\right)_{3}\right]^{+}$. Very similar results were found using both species, being slightly more favourable the protonation with TFA $\left(\Delta \mathrm{G}=-20.9 \mathrm{kcal}^{\mathrm{mol}}{ }^{-1} ; \Delta \mathrm{G}^{\ddagger}=2.9 \mathrm{kcal}^{\mathrm{mol}}{ }^{-1}\right)$ than with $\left[\mathrm{H}_{3} \mathrm{O}\left(\mathrm{H}_{2} \mathrm{O}\right)_{3}\right]^{+}\left(\Delta \mathrm{G}=-16.4 \mathrm{kcal} \mathrm{mol}^{-1} ; \Delta \mathrm{G}^{\ddagger}=5.3 \mathrm{kcal} \mathrm{mol}^{-1}\right)$

In order to study the processes mediated by Ru-NPs, we used a model that includes 57 ruthenium (44 at the surface) and 88 hydrogen atoms $\left(\mathrm{Ru}_{57} \mathrm{H}_{88}\right.$, Fig. 5). We considered this structure as a good representation of the active species generated under reductive potentials in acidic media, able to act as an efficient hydride transfer agent. The model choice and the number of hydrogen atoms is based on Comas-Vives et al. results. ${ }^{52}$ Their work showed that this model is a good compromise between accuracy and computational cost and that the number of hydrogen atoms per surface ruthenium is close to the double of surface ruthenium atoms in pristine nanoparticles

Hydride Transfer to $\mathrm{PhNO}_{2}$ vs Hydride Protonation. Once the active species able to perform hydride transfer processes are generated, two potential reactions can take place: hydride transfer to nitrobenzene and HER. Fig. 6 shows the comparison of the kinetics and thermodynamics of these processes in presence of model systems for a) ox-CF and b) Ru-CF. Fig. 7 shows some optimized structures.

Regarding the reactivity in presence of the ox-CF, calculations show that the hydride transfer to $\mathrm{PhNO}_{2}$ is slightly endothermic $\left(\Delta G=+3.6 \mathrm{kcal} \mathrm{mol}^{-1}\right)$ but this is clearly compensated by the subsequent protonation of $\mathrm{PhNO}_{2} \mathrm{H}$, which leads to PhNO (1) and a water molecule (origin of the exothermicity; $\Delta G=-108.9 \mathrm{kcal} \mathrm{mol}^{-1}$ ). The competitive $\mathrm{H}_{2}$ formation is also thermodynamically favourable both from TFA and hydronium type molecule $\left[\mathrm{H}_{3} \mathrm{O}\left(\mathrm{H}_{2} \mathrm{O}\right)_{3}\right]^{+}$, obtaining computed $\Delta \mathrm{G}$ values of -11.6 and $-6.2 \mathrm{kcal} \mathrm{mol}^{-1}$, respectively. From a kinetic point of view, the hydride transfer to $\mathrm{PhNO}_{2}$ is favoured with respect to HER by at least $9.2, \mathrm{kcal} \mathrm{mol}^{-1}$. HER reaction is more favoured when TFA is used as proton source. These results are in accordance with the high faradaic yields found for nitrobenzene reduction (see above).

Nitrobenzene hydrogenation and $\mathrm{H}_{2}$ formation on Ru-NPs start with the adsorption of the reacting substrates to the 

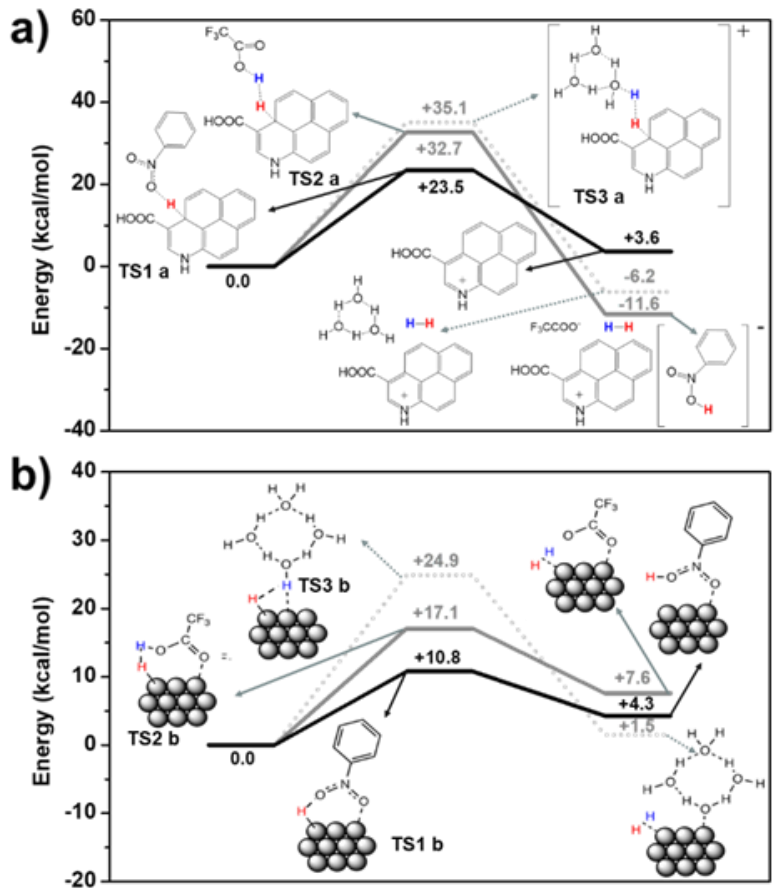

Fig. 6 Comparison of energetics for the hydride transfer to $\mathrm{PhNO}_{2}$ (black line) and HER (grey lines) using a) ox-CF and b) Ru-CF electrocatalytic models. Hydride protonation can be carried out by TFA (solid grey line) or by $\left[\left(\mathrm{H}_{3} \mathrm{O}\right)\left(\mathrm{H}_{2} \mathrm{O}\right)_{3}\right]^{+}$(dashed grey line). Energies are given in $\mathrm{kcal}^{\mathrm{mol}}{ }^{-1}$.


b)
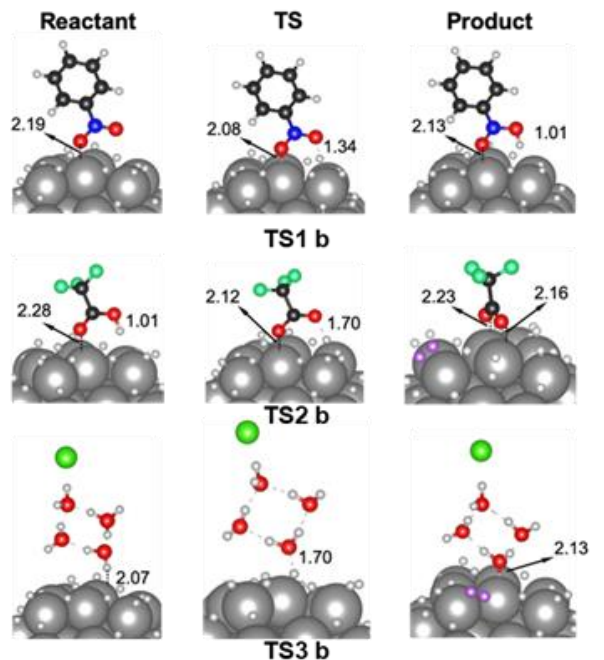

Fig. 7 Optimized structures found for $\mathrm{PhNO}_{2}$ hydrogenation and HER using TFA and hydronium ion as source of protons: a) transition states shown in Figure 6a for ox-CF model system and $b$ ) the starting materials, transition states and final products using Ru-CF as catalytic model system as shown in Figure 6b. Distances are given in $\AA$.

nanoparticle surface (Table S2). This adsorption is more favourable for nitrobenzene and TFA than for hydronium ion $\left[\mathrm{H}_{3} \mathrm{O}\left(\mathrm{H}_{2} \mathrm{O}\right)_{3}\right]^{+}$due to the formation of $\mathrm{Ru} \cdots \mathrm{O}$ interactions (see S.I. for further details). As found for the carbon fibres, the hydride transfer to the adsorbed nitrobenzene is slightly unfavourable $\left(\Delta \mathrm{E}=4.3 \mathrm{kcal} \mathrm{mol}^{-1}\right)$, but the high exothermicity of the protonation step makes the formation of $\mathrm{PhNO}+\mathrm{H}_{2} \mathrm{O}$ largely favourable. The energy barrier for the hydride transfer to the adsorbed $\mathrm{PhNO}_{2}$ species is computed to be $10.8 \mathrm{kcal} \mathrm{mol}^{-1}$, thus suggesting it is kinetically easy. The hydride protonation in presence of Ru-NPs is easier when involving TFA than $\left[\left(\mathrm{H}_{3} \mathrm{O}\right)\left(\mathrm{H}_{2} \mathrm{O}\right)_{3}\right]^{+}$. The energy barrier is computed to be $17.1 \mathrm{kcal}$ $\mathrm{mol}^{-1}$ from adsorbed TFA. This value is higher than that computed for the $\mathrm{PhNO}_{2}$ hydride transfer. The energy difference between the two processes is slightly smaller than for the oxidized fibres, indicating that HER (which is in both cases kinetically less favoured) could be a better competing reaction when using Ru-CF rather than when using ox-CF. These results agree with the experimentally measured faradaic yields for the two systems. A potential explanation of the large difference between the HER energy barriers when involving TFA and $\left[\left(\mathrm{H}_{3} \mathrm{O}\right)\left(\mathrm{H}_{2} \mathrm{O}\right)_{3}\right]^{3+}$ could derive from the nature and the strength of the substrate-Ru-NP interaction. Indeed, the Ru $\cdots O$ interaction increases the acidity of TFA favouring the hydride protonation.

From $\mathrm{PhNO}$ (1) to $\mathrm{PhNH}_{2}$ (3). Evolution of $\mathrm{PhNO}$ species formed from the first hydrogenation process (hydride transfer + protonation) to aniline consists of two consecutive hydrogenation steps (Scheme 2). Every hydrogenation step has been considered as an initial hydride transfer with a nonnegligible energy barrier, followed by the protonation process, which is generally very exothermic, mainly barrier-less and does not involve the electrocatalyst. The hydride transfer to PhNO (1) results in deprotonated hydroxyaniline. This process is exothermic in presence of ox-CF by $-11.7 \mathrm{kcal} \mathrm{mol}^{-1}$. Moreover, the energy barrier is low $\left(\Delta \mathrm{G}^{\ddagger}=12.6 \mathrm{kcal} \mathrm{mol}^{-1}\right)$ which indicates that the process is kinetically favourable (Scheme 2a). In addition, the protonation of deprotonated hydroxyaniline is also very favourable, suggesting that once PhNO (1) is formed, it easily evolves to $\mathrm{PhNHOH}$ (2).

a)



b)

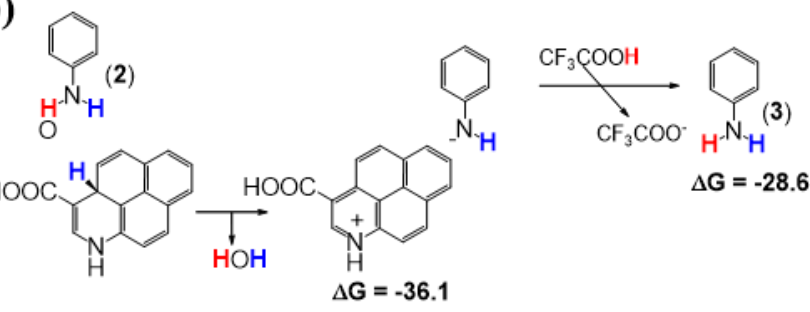

Scheme 2 Catalytic evolution of PhNO (1) consisting in two consecutive hydrogenation and protonation steps: a) forming hydroxyaniline (2) and b) aniline (3). Energy values are given in $\mathrm{kcal} \mathrm{mol}^{-1}$. 



Scheme 3 Catalytic evolution of Ph-NO to aniline through two successive hydrogenation/protonation steps with Ru-NPs. Energies in $\mathrm{kcal}^{\mathrm{mol}}{ }^{-1}$

Calculations for the second hydrogenation step indicate that hydride transfer to the $\mathrm{OH}$ group of hydroxyaniline to generate a water molecule and deprotonated aniline is very exothermic (-36.1 $\mathrm{kcal} \mathrm{mol}^{-1}$, Scheme $\left.2 \mathrm{~b}\right)$. In this case, transition state has not been located, indicating that this reaction is barrierless or proceeds through a very shallow barrier. Further protonation of deprotonated aniline is very favourable. Consequently, nitrobenzene hydrogenation (Fig. 6) seems to be the ratedetermining step. Once PhNO (1) is generated, its reduction to aniline (3) should consecutively occur.

With the aim of analysing if these two steps are also straightforward in presence of Ru-NPs, we computed the corresponding reaction energies. Results are reported in Scheme 3 and show that PhNO (1) hydrogenation is similar to that found for the ox-CF and it is favourable by $-14.9 \mathrm{kcal} \mathrm{mol}^{-1}$. On the other hand, the hydrogenation of $\mathrm{PhNHOH}$ shows larger differences. The resulting products are the same for the two catalytic systems. However, the strong Ru-NPs- $\mathrm{H}_{2} \mathrm{O}$ interaction and the Ru-PhNH makes the reaction even more exothermic $\left(\Delta \mathrm{E}=-50.3 \mathrm{kcal} \mathrm{mol}^{-1}\right)$. The ability of Ru-NPs to coordinate the reacting substrates changes the thermodynamics in comparison with the ox-CF system. In any case, the initial $\mathrm{PhNO}_{2}$ hydrogenation to PhNO (1) appears to be the more challenging step also when using Ru-NPs (Fig. 6b).

Overall, calculations suggest that aniline (3) should be easily formed with the two catalytic systems. However, according to the experimental data, aniline (3) is only a minor product detected in the reaction outcome. Justification of this observation is found in the next section.

Dimerization process. Since the major product observed in the electrolysis experiments (see Experimental Results section above) is the dimeric compound azoxynitrobenzene (4), we decided to evaluate the thermodynamics of its formation from the reaction of nitrosobenzene (1) and hydroxyaniline (2) intermediates. Effectively, condensation of such compounds is highly favoured, as it should be expected for the formation of a water molecule, which serves as an efficient driving force of the process (Scheme 4). Thus, while hydroxyaniline (2) is slowly being generated, it efficiently reacts with the excess of nitrosobenzene (1) to generate the main final product of this electrocatalytic system, azoxynitrobenzene (4).

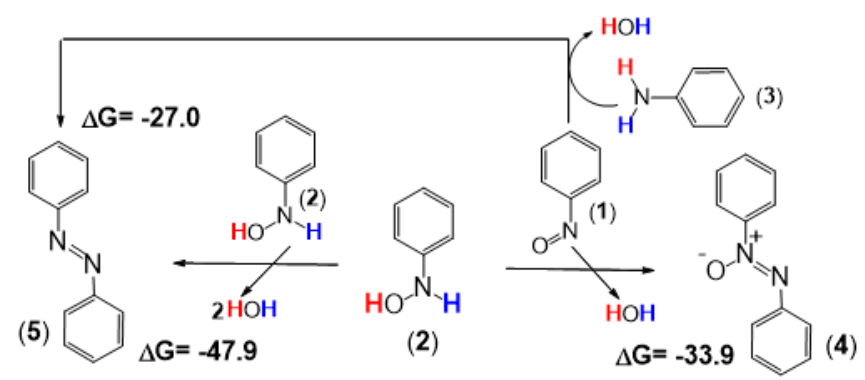

Scheme 4 Dimerization processes towards formation of azoxynitrobenzene (4) and azobenzene (5) (energy values are given in $\mathrm{kcal} \mathrm{mol}^{-1}$ ).

Furthermore, formation of the diazo compound (5) that has been detected in residual amounts can be explained by the dimerization of two hydroxyaniline (2) molecules (Scheme 4). Considering that during the reaction, hydroxyaniline (2) coexists with an excess on nitrosobenzene (1), this alternative process is less probable, which agrees with the residual amounts of such species experimentally detected. Finally, condensation of aniline and nitrosobenzene (1) could also account for the formation of the diazo compound (5), which could be responsible for the disappearance over time of aniline (3).

Dimerization processes require significant concentrations of monomer species. Therefore, at short reaction times, when concentration of products is still low, direct formation of aniline is plausible through the three consecutive hydrogenation steps presented above. However, after longer electrolysis, concentration of products increases, and dimeric structures can appear through exothermic condensations. Thus, aniline is expected to be formed at short reaction times as indeed experimentally observed (Fig. 4). It is also in good agreement with the experimental observation that both dimeric products are produced at longer reaction times. The fact that the major product found is the azoxynitrobenzene (4) species indicates that its hydrogenation is unfavourable as is demonstrated in the next section.

Evaluation of possible evaluation of azoxynitrobenzene (4). The hydride transfers to azoxynitrobenzene (4) and to the other dimeric species (diphenyldiazene (5) and diphenylhidrazine (6)) involving the two catalytic systems are summarized in Schemes 5 and 6 . With ox-CF, the hydride transfer to azoxynitrobenzene (4) (Scheme 5a) is endothermic $\left(\Delta G=+5.9 \mathrm{kcal} \mathrm{mol}^{-1}\right)$ and the computed Gibbs energy barrier $\left(\Delta \mathrm{G}^{\ddagger}=47.4 \mathrm{kcal} \mathrm{mol}^{-1}\right)$ indicates that the process is highly kinetically hampered. This suggests that azoxynitrobenzene (4) would hardly be hydrogenated, even though protonation of the resulting product to form a water molecule and the diazo compound is highly exothermic. This agrees with azoxynitrobenzene (4) being the major product of nitrobenzene hydrogenation, the small portions of diazo compound observed experimentally being likely formed by the dimerization processes.

The potential formation of aniline from the diazo compound (5) in presence of ox-CF has also been considered (Scheme 5b and $5 \mathrm{c}$ ). The obtained results indicate that under the reaction conditions, diphenyldiazene (5) would easily evolve to diphenylhidrazine (6). Finally, the hydride transfer to this hydrazine derivative (6) intermediate leading to aniline 
a)
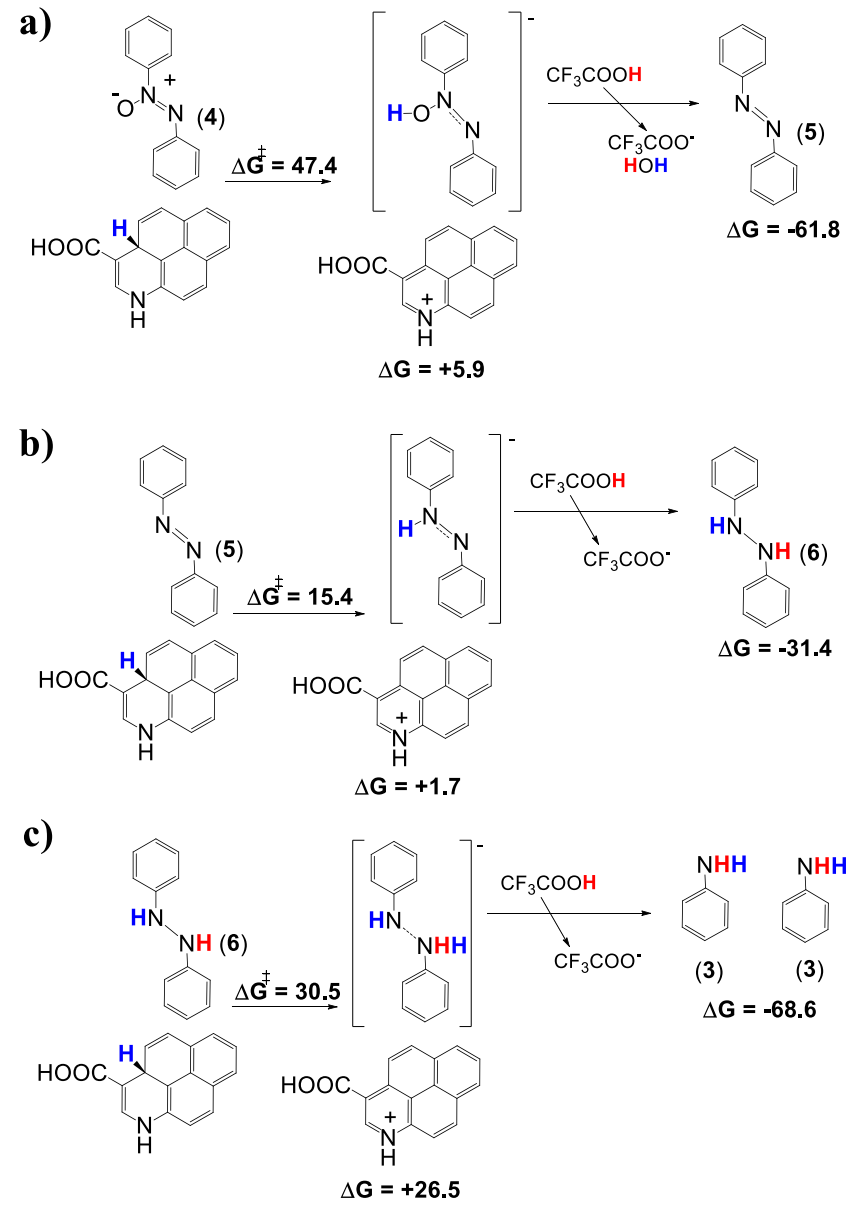

Scheme $\mathbf{5}$ Catalytic evolution of hydrogenation of azoxynitrobenzene towards a) the diazo compound, b) the diphenyl hydrazine product and c) aniline (energy values are given in $\mathrm{kcal} \mathrm{mol}^{-1}$ ).

a)

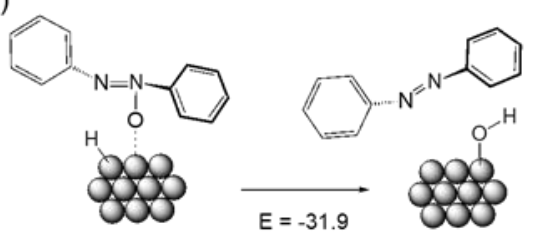

b)



c)



Scheme 6 Azoxynitrobenzene conversion to aniline through three successive hydrogenation/protonation steps with Ru-NPs. Energies in $\mathrm{kcal}^{\mathrm{mol}}{ }^{-1}$ formation is very endothermic $\left(\Delta \mathrm{G}=+26.5 \mathrm{kcal} \mathrm{mol}^{-1}\right)$ and kinetically hampered $\left(\Delta \mathrm{G}^{\ddagger}=30.5 \mathrm{kcal} \mathrm{mol}^{-1}\right.$, Scheme $\left.5 \mathrm{c}\right)$.

Therefore, although further protonation is calculated to be very exothermic, hydrogenation of diphenylhidrazine (6) does not seem to be the path for the formation of aniline (3). Indeed, the observed aniline is expected to be formed by successive hydrogenation of $\mathrm{PhNO}_{2}$ without dimerization, while the major dimeric product is azoxynitrobenzene (4), which presents the highest hydride transfer Gibbs energy barrier. The reactivity of azoxynitrobenzene (4) with the Ru-CF has also been explored, considering the thermodynamics of the three potential hydrogenation steps (Scheme 6a to 6c) as well as the transition state for the hydride transfer to azoxynitrobenzene (4), which appeared to be a key step in the organocatalytic system. Fig. 8 shows the optimized structures of azoxynitrobenzene (4), diphenyldiazene (5) and the transition state connecting these two intermediates.

The reactivity of azoxynitrobenzene (4) with the Ru-CF has also been explored, considering the thermodynamics of the three potential hydrogenation steps (Scheme 6a to 6c) as well as the transition state for the hydride transfer to azoxynitrobenzene (4), which appeared to be a key step in the organocatalytic system. Fig. 8 shows the optimized structures of azoxynitrobenzene (4), diphenyldiazene (5) and the transition state connecting these two intermediates.

The hydrogenation pathways found for azoxynitrobenzene (4) using Ru-CF are significantly different than those calculated for ox-CF. As observed for the hydrogenation of $\mathrm{Ph}-\mathrm{NHOH}$ (2), the resulting products ( $\mathrm{PhNNPh}+\mathrm{Ru}-\mathrm{NPs}-\mathrm{OH}$ ) using Ru-CF are the consequence of the formation of a $\mathrm{Ru}-\mathrm{OH}$ bond at the nanoparticle surface. Remarkably, despite the large exothermicity of the reaction $\left(\Delta \mathrm{E}=-31.9 \mathrm{kcal} \mathrm{mol}^{-1}\right)$, the computed energy barrier is high ( $\left.+24.9 \mathrm{kcal} \mathrm{mol}^{-1}\right)$ due to the large electronic reorganization to favour the concerted formation/cleavage of the Ru $\cdots \mathrm{O}$ and $\mathrm{N} \cdots \mathrm{O}$ bonds. Moreover, the two subsequent hydrogenation steps are thermodynamically favourable (Scheme 6), indicating that aniline formation from azoxynitrobenzene (4) is thermodynamically feasible. However, as in the case of ox-CF, this is not expected to be the main route for aniline formation. This is due to the large energy barrier of the hydride transfer to azoxynitrobenzene (4), which should be the major dimeric species, as found experimentally.

Summarizing, calculations on the evolution of azoxynitrobenzene (4) suggest that this species could hardly be

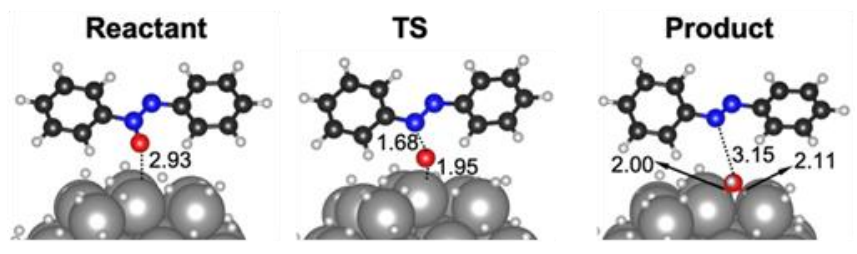

Fig, 8 Optimized structures for azoxynitrobenzene intermediate adsorbed on $\mathrm{H}_{88} \mathrm{Ru}_{57}$ nanoparticle, the diphenyldiazene resulting from its hydrogenation and the transition state connecting them. Distances in $\AA$ and energies in $\mathrm{kcal} \mathrm{mol}^{-1}$ 




(1)
(2)



(4)



(5)
Scheme 7 General scheme for the nitrobenzene reduction reaction proposed for the two electrocatalytic approaches studied.

reduced regardless the nature of the electrocatalyst. Thus, despite the different reactivity expected for ox-CF and Ru-CF, the chemical identity of the final products should not vary, being azoxynitrobenzene (4) the major product.

Overall, our calculations show a reaction mechanism for the nitrobenzene hydrogenation that is consistent with the experimental data. Despite the different reactivities observed for the two electrocatalysts for some particular steps, the mechanisms for the two systems share the main general issues, which are summarized in Scheme 7: nitrobenzene is hydrogenated following a first 2-electron and 2 proton transfer steps leading to the formation of nitrosobenzene (1), which is converted to hydroxyaniline (2) following a further 2-electron and 2 protons reduction. While this species is being formed two processes can occur: a) further hydrogenation until aniline product (3) (which is detected in low amounts) or b) condensation with nitrosobenzene (1) to produce azoxynitrobenzene (4) (which is observed as main product). This dimeric species cannot be further reduced, appearing as the final product. In addition, residual amounts of diazo compound (5) found in the reaction outcome seems to be the result of dimerization of residual amounts of hydroxyaniline (2) or the recombination of aniline (3) and nitrosobenzene (1). Controversially, according to our theoretical data, diazo species (5) should be easily reduced to hydrazine compound, which should accumulate because its further reduction is unfavourable. However, the known high reactivity of hydrazine compounds can account for its further evolution being impossible its detection under the working conditions.

\section{Conclusions}

The conclusions section should come in this section at the end of the article, before the acknowledgements. Two electrocatalytic systems of very different nature result on comparable outputs for $\mathrm{PhNO}_{2}$ hydrogenation, which is kinetically favoured with respect to HER. Some subtle differences can be distinguished from our results. Combination of experimental results and DFT calculations indicates that HER is a more significant competitor when Ru-CF are used as catalyst. Theoretical calculations also show that Ru-CF is intrinsically more reactive than the organocatalytic system (ox-
CF). However, this trend is not necessarily observed experimentally as the concentration of active centres on the electrode surface may significantly vary.

The main product experimentally observed for nitrobenzene hydrogenation is the azoxynitrobenzene dimeric species, while aniline is formed in minor quantities during the first stages of the electrocatalytic process. However, according to DFT results, once the initial hydrogenation rate determining step occurs (from $\mathrm{PhNO}_{2}$ to $\mathrm{PhNO}$ ), successive hydrogenation steps to generate aniline (from $\mathrm{PhNO}$ to $\mathrm{PhNH}(\mathrm{OH}$ ) and from $\mathrm{PhNH}(\mathrm{OH})$ to $\mathrm{PhNH}_{2}$ ) are highly favoured. In parallel to aniline formation, dimeric azoxynitrobenzene compound is generated as a consequence of the highly favourable condensation of $\mathrm{PhNO}$ and $\mathrm{PhNH}(\mathrm{OH})$.

Overall, this work presents an in-depth understanding of the catalytic behaviour of an organic- and a metal-based material that previously have been used as electrocatalysts for HER. In contrast, we have shown how hydrogenation of $\mathrm{PhNO}_{2}$ efficiently competes with HER. Thus, the methodology reported herein can be applied to the electrochemical remediation of an important class of pollutants (nitro aryl compounds). In a more general perspective, these insights may contribute to the future designs of more efficient catalytic systems for hydrogen production, electrochemical waste-water treatments or use of hydrogenation/dehydrogenation based energetic vectors.

\section{Experimental}

\section{Materials}

All reagents, solvents and materials were purchased from commercial sources and used without further purification. Specifically, fabric of carbon fibre (Twill $2 \times 23 \mathrm{~K}$ weight $200 \mathrm{~g} / \mathrm{m}^{2}$ width $1200 \mathrm{~mm}$, Model HA2301) was purchased from ClipCarbono.

\section{Electrode Preparation}

The commercial carbon fibre is prepared in a $6 \mathrm{~cm}$ long bunch of fibres. Then, it is joined to a copper wire and tight with a Teflon tape. The hand-made electrodes are modified using two different approaches, namely: 1) oxidative treatment of the carbon fibre and 2) ex-situ deposition of Ru-NPs. For the oxidized CF brushes, they are treated 30 minutes with sulfuric acid $(98 \%)$ at room temperature with stirring and later they are immersed into a mixture $1: 1$ of $\mathrm{H}_{2} \mathrm{SO}_{4} / \mathrm{H}_{2} \mathrm{O}_{2}$. The mixture should be freshly prepared to obtain its stronger oxidative potential and thus, be able to oxidize the carbon fibre. Finally, the electrodes are washed and sonicated in distilled water to neutralize its surface, later washed in ethanol and dried with a heat gun. Characterization of this material was previously reported and confirms that the oxidation process changes the chemical features of the CF surface (generation of carboxylic groups, transforming pyridinic fragments into nicotinic ones) whereas keep its bulk properties and morphology. ${ }^{21}$ For the Rubased CF, $2 \mathrm{~cm}$ of CF electrodes were soaked overnight in a THF $(10 \mathrm{~mL})$ crude dispersion of RuPP NPs ${ }^{27,53}$ inside a Fisher-Porter bottle under an Ar atmosphere. Then, the supernatant was 
removed through cannula and the resulting $\mathrm{CF}$ materials were rinsed with pentane $(3 \times 10 \mathrm{~mL})$ and dried under vacuum. RuPP@pCF. TEM: $\varnothing=1.8 \pm 0.3 \mathrm{~nm}$. ICP(Ru\%): 0.47\%.

\section{Electrochemistry}

Electrochemical experiments were performed under an argon atmosphere at room temperature in $\mathrm{CH}_{3} \mathrm{CN}$. Sodium perchlorate $\left(\mathrm{NaClO}_{4}\right)$ was used as supporting electrolytes. Measurements were carried out using an Ivium CompaqStat potentiostat interfaced with a computer. A standard threeelectrode electrochemical cell was used with $\mathrm{Ag} / \mathrm{AgCl}$ reference electrode. The working electrode was carbon fibre brush: pristine, oxidized and modified with inorganic nanoparticles. The counter electrode was a pristine carbon fibre brush.

\section{Gas Chromatography}

The evolution of the nitrobenzene during the electrocatalytic reaction was monitored by gas chromatography, by injecting samples of the intern atmosphere to an Agilent 7820A GC system equipped with a mass spectroscopy detector (5977B MSD). For gas chromatography quantification of nitrobenzene and its derivatives, the solvent of the working electrode solution is reduced at low pressure and then it is solved with $1 \mathrm{~mL}$ of $\mathrm{CHCl}_{3}$ which is able to solve the nitrobenzene and its derivatives but not the inorganic salt of the electrolyte. An aliquot of $0.2 \mathrm{~mL}$ of the solution is mixed with $0.2 \mathrm{~mL}$ of methylnaphthalene as standard. A calibrate of nitrobenzene, nitrosobenzene, azoxynitrobenzene, diphenylazobenzene and aniline was carried out enabling the quantification of the products.

\section{Computational Details}

The main text of the article should appear here with headings Quantum chemistry calculations were carried out using the density functional theory (DFT). For the organocatalytic system, geometry optimizations were performed using the M06-2X functional ${ }^{43}$ in combination with the $6-311 G(d, p)$ basis set. ${ }^{44}$ Solvent effects were included with the solvation model density $(\mathrm{SMD})^{45}$ and considering acetonitrile $(\varepsilon=37.5)$ as solvent. Graphitic surface was modelled using a fragment composed by 4 fused aromatic rings ( 1 pyridine +3 benzenes) as a compromise between performance and computational cost. We introduced a carboxylic group in the meta position versus pyridine nitrogen. All optimizations were performed without any geometrical constraint and harmonic vibrational frequencies have been also evaluated at the same level of theory to characterize minima and transition states in the potential energy surface. Transition states have been connected to products by optimization of geometries slightly modified from the transition states. All the calculations were performed using the Gaussian09 program. ${ }^{54}$

For modelling the reactivity with Ru-NPs, we use the $\mathrm{PBE}^{48}$ functional as implemented in the VASP code. ${ }^{46,47}$ Grimme (D2) empirical correction was added to account for dispersion interactions. ${ }^{49}$ The core electrons are described by ultrasoft pseudopotential ${ }^{55,56}$ and the external ones by plane wave basis set, with a kinetic energy cutoff of $500 \mathrm{eV}$. With the aim of minimizing replica interactions, a cubic cell of $25 \AA$ was employed. The $k$ point grid includes the a point only, as a consequence of the discrete nature of the system. The energy convergence criteria were fixed to $10^{-5}$ and $10^{-4} \mathrm{eV}$ for electronic and geometry relaxations, respectively. Solvent effects were included during the optimization with the implicit continuum model implemented in $\mathrm{VASPsol}^{57}$ and using acetonitrile as solvent $(\varepsilon=37.5)$. Transition states were located by using climbing image nudged elastic band (Cl-NEB) method without including solvent effects. ${ }^{58,59}$ Six or eight images per NEB were used. The highest in energy image was used for locating the final transition state by performing a geometry optimization with the quasi-Newton algorithm implemented in VASP. Convergence was considered to be achieved when forces were smaller than $0.02 \mathrm{eV} / \AA ̊$. For the case of the hydronium ion, the transition state was located by performing restricted optimizations with solvation. The $\mathrm{O}-\mathrm{H}$ distance was fixed to and the highest in energy point was used as starting point for localizing the transition state. The energies reported along the text are all given in $\mathrm{kcal} \mathrm{mol}^{-1}$.

\section{Conflicts of interest}

There are no conflicts to declare.

\section{Acknowledgements}

This work was supported by Spanish Ministerio de Economia y Competitividad (MINECO) (CTQ2015-64261-R, CTQ2017-89132$\mathrm{P}$ and RTI2018-095038-B-I00), and the Generalitat de Catalunya (2017SGR1323). We acknowledge the generous allocation of computer time at the Centro de Computación Científica at the Universidad Autónoma de Madrid (CCC-UAM) and the Consorci de Serveis Universitaris de Catalunya (CSUC). "Comunidad de Madrid" and European Structural Funds (S2018/NMT-4367) are also acknowledged. J.G.-A. acknowledges Serra Húnter Program and KP CNRS.

\section{Notes and references}

11 S. Ahmed, M. G. Rasul, R. Brown and M. A. Hashib, J. Environ. Manage., 2011, 92, 311-330.

22 U. I. Gaya and A. H. Abdullah, J. Photochem. Photobiol. C Photochem. Rev., 2008, 9, 1-12.

33 W.-D. Oh, Z. Dong and T.-T. Lim, Appl. Catal. B Environ., 2016, 194, 169-201.

44 G. Liang, L. He, H. Cheng, W. Li, X. Li, C. Zhang, Y. Yu and F. Zhao, J. Catal., 2014, 309, 468-476.

55 J. S. Sung, K. Y. Choo, T. H. Kim, A. L. Tarasov, O. P. Tkachenko and L. M. Kustov, Int. J. Hydrog. Energy, 2008, 33, 2721-2728.

66 L. M. Kustov, A. L. Tarasov and B. P. Tarasov, Int. J. Hydrog. Energy, 2013, 38, 5713-5716.

77 S. J. C. Cleghorn and D. Pletcher, Electrochimica Acta, 1993, 38, 425-430.

88 J. S. Yoo, R. Christensen, T. Vegge, J. K. Nørskov and F. Studt, ChemSusChem, 2016, 9, 358-363. 
99 C. G. Morales-Guio, L.-A. Stern and X. Hu, Chem. Soc. Rev. 2014, 43, 6555-6569.

1010 W. Wang, Q. Zhao, J. Dong and J. Li, Hysydays, 2011, 36, 7374-7380.

1111 J. D. Blakemore, A. Gupta, J. J. Warren, B. S. Brunschwig and H. B. Gray, J. Am. Chem. Soc., 2013, 135, 18288-18291.

1212 C. Hu, L. Zhang and J. Gong, Energy Environ. Sci., 2019, 12, 2620-2645.

1313 S. Grau, S. Berardi, A. Moya, R. Matheu, V. Cristino, J. J. Vilatela, C. A. Bignozzi, S. Caramori, C. Gimbert-Suriñach and A. Llobet, Sustain. Energy Fuels, 2018, 2, 1979-1985.

1414 Y. Xu, M. Kraft and R. Xu, Chem Soc Rev, 2016, 45, 30393052.

1515 W. Cui, Q. Liu, N. Cheng, A. M. Asiri and X. Sun, Chem Commun, 2014, 50, 9340-9342.

1616 S. Y. Tee, K. Y. Win, W. S. Teo, L.-D. Koh, S. Liu, C. P. Teng and M.-Y. Han, Adv. Sci., 2017, 4, 1600337.

1717 A. Moya, M. Barawi, B. Alemán, P. Zeller, M. Amati, A. Monreal-Bernal, L. Gregoratti, V. A. de la Peña O'Shea and J. J. Vilatela, Appl. Catal. B Environ., 2020, 118613.

1818 C.-H. Chen, D. Wu, Z. Li, R. Zhang, C.-G. Kuai, X.-R. Zhao, C.-K. Dong, S.-Z. Qiao, H. Liu and X.-W. Du, Adv. Energy Mater., 2019, 9, 1803913.

1919 J. N. Tiwari, A. M. Harzandi, M. Ha, S. Sultan, C. W. Myung, H. J. Park, D. Y. Kim, P. Thangavel, A. N. Singh, P. Sharma, S. S. Chandrasekaran, F. Salehnia, J.-W. Jang, H. S. Shin, Z. Lee and K. S. Kim, Adv. Energy Mater., 2019, 9, 1900931.

2020 J. Creus, J. De Tovar, N. Romero, J. García-Antón, K. Philippot, R. Bofill and X. Sala, ChemSusChem, 2019, 12, 24932514.

2121 O. G. Moral, A. Call, F. Franco, A. Moya, J. A. NietoRodríguez, M. Frias, J. L. G. Fierro, M. Costas, J. Lloret-Fillol, J. Alemán and R. Mas-Ballesté, Chem. - Eur. J., 2018, 24, 33053313.

2222 B. Alberts, D. Bray, J. Lewis, M. Raff, K. Roberts and J. D. Watson, in Molecular Biology of the Cell., Garland, New York \& London, 3rd edn., 3rd edn., 2002.

2323 J. M. Berg, J. L. Tymoczko and L. Stryer, Biochemistry, W. H. Freeman, New York, 5th edn, 2002.

2424 S. G. Ouellet, A. M. Walji and D. W. C. Macmillan, Acc. Chem. Res., 2007, 40, 1327-1339.

2525 S.-L. You, Chem. - Asian J., 2007, 2, 820-827.

2626 L. Simón and J. M. Goodman, J Am Chem Soc, 2008, 130 8741-8747.

2727 J. Creus, L. Mallón, N. Romero, R. Bofill, A. Moya, J. L. G. Fierro, R. Mas-Ballesté, X. Sala, K. Philippot and J. GarcíaAntón, Eur. J. Inorg. Chem., 2019, 2071-2077.

2828 Y. Zhao, L. Lin and M. Hong, Front. Environ. Sci. Eng., 2019, 13, 29.

2929 P. S. Majumder and S. K. Gupta, Water Res., 2003, 37, 4331-4336.

3030 J. Wang, H. Lu, Y. Zhou, Y. Song, G. Liu and Y. Feng, J. Hazard. Mater., 2013, 252-253, 227-232.

3131 F. Luan, W. D. Burgos, L. Xie and Q. Zhou, Environ. Sci. Technol., 2010, 44, 184-190.

3232 Y. Gao, D. Ma, C. Wang, J. Guan and X. Bao, Chem Commun, 2011, 47, 2432-2434.

3333 X. Huang, Y. Li, Y. Li, H. Zhou, X. Duan and Y. Huang, Nano Lett., 2012, 12, 4265-4270.

3434 A. Maldotti, L. Andreotti, A. Molinari, S. Tollari, A. Penoni and S. Cenini, J. Photochem. Photobiol. Chem., 2000, 133 129-133.

3535 H. Tada, T. Ishida, A. Takao and S. Ito, Langmuir, 2004, 20, 7898-7900.

3636 F. Haber, Z Elektrochem Angew Phys Chem, 1898, 4, 506.

3737 Y. Zhang, L. Zeng, X. Bo, H. Wang and L. Guo, Anal. Chim. Acta, 2012, 752, 45-52.
3838 Z. Ogumi, M. Inaba, S. Ohashi, M. Uchida and Z. Takehara, Electrochimica Acta, 1988, 33, 365-369.

3939 T. Meisel and J. Moser, Geostand. Geoanalytical Res., 2004, 28, 233-250.

4040 Y. Chen, L. Xiong, W. Wang, X. Zhang and H. Yu, Front Environ. Sci. Eng., 2015, 9, 897-904.

4141 C. Liu, A.-Y. Zhang, D.-N. Pei and H.-Q. Yu, Environ. Sci. Technol., 2016, 50, 5234-5242.

4242 N. Daems, J. Wouters, C. Van Goethem, K. Baert, C. Poleunis, A. Delcorte, A. Hubin, I. F. J. Vankelecom and P. P. Pescarmona, Appl. Catal. B Environ., 2018, 226, 509-522.

4343 Y. Zhao and D. G. Truhlar, Theor. Chem. Acc., 2007, 120, 215-241.

4444 W. J. Hehre, R. Ditchfield and J. A. Pople, J. Chem. Phys. 1972, 56, 2257-2261.

4545 A. V. Marenich, C. J. Cramer and D. G. Truhlar, J. Phys. Chem. B, 2009, 113, 6378-6396.

4646 G. Kresse and J. Furthmüller, Phys. Rev. B, 1996, 54, 11169-11186.

4747 G. Kresse and J. Hafner, Phys. Rev. B, 1993, 47, 558-561.

4848 J. P. Perdew, K. Burke and M. Ernzerhof, Phys. Rev. Lett., 1996, 77, 3865-3868.

4949 S. Grimme, J. Comput. Chem., 2004, 25, 1463-1473.

$5050 \mathrm{~W}$. Koch and M. C. Holthausen, in A Chemist's Guide to Density Functional Theory, John Wiley \& Sons, Ltd, 2001, pp. i-xiii.

5151 W. N. Hansen and G. J. Hansen, Surf. Sci., 2001, 481, 172184.

5252 A. Comas-Vives, K. Furman, D. Gajan, M. C. Akatay, A Lesage, F. H. Ribeiro and C. Copéret, Phys. Chem. Chem. Phys. 2016, 18, 1969-1979.

5353 J. Creus, S. Drouet, S. Suriñach, P. Lecante, V. Collière, R. Poteau, K. Philippot, J. García-Antón and X. Sala, ACS Catal., 2018, 8, 11094-11102.

5454 M. J. Frisch, G. W. Trucks, H. B. Schlegel, G. E. Scuseria, M A. Robb, J. R. Cheeseman, G. Scalmani, V. Barone, B. Mennucci, G. A. Petersson, H. Nakatsuji, M. Caricato, X. Li, H. P. Hratchian, A. F. Izmaylov, J. Bloino, G. Zheng, J. L. Sonnenberg, M. Hada, M. Ehara, K. Toyota, R. Fukuda, J. Hasegawa, M. Ishida, T. Nakajima, Y. Honda, O. Kitao, H. Nakai, T. Vreven, J. A. Montgomery Jr., J. E. Peralta, F. Ogliaro, M. Bearpark, J. J. Heyd, E. Brothers, K. N. Kudin, V. N. Staroverov, R. Kobayashi, J. Normand, K. Raghavachari, A. Rendell, J. C. Burant, S. S. Iyengar, J. Tomasi, M. Cossi, N. Rega, J. M. Millam, M. Klene, J. E. Knox, J. B. Cross, V. Bakken, C. Adamo, J. Jaramillo, R. Gomperts, R. E. Stratmann, O. Yazyev, A. J. Austin, R. Cammi, C. Pomelli, J. W. Ochterski, R. L. Martin, K. Morokuma, V. G. Zakrzewski, G. A. Voth, P. Salvador, J. J. Dannenberg, S. Dapprich, A. D. Daniels, Farkas, J. B. Foresman, J. V. Ortiz, J. Cioslowski and D. J. Fox, Gaussian 09 Revision E.01, Wallingford CT: Gaussian, Inc., 2009.

5555 G. Kresse and D. Joubert, Phys. Rev. B, 1999, 59, 17581775 .

5656 P. E. Blöchl, Phys. Rev. B, 1994, 50, 17953-17979.

5757 K. Mathew, R. Sundararaman, K. Letchworth-Weaver, T. A Arias and R. G. Hennig, J. Chem. Phys., 2014, 140, 084106.

5858 G. Henkelman, B. P. Uberuaga and H. Jónsson, J. Chem. Phys., 2000, 113, 9901-9904.

5959 G. Henkelman and H. Jónsson, J. Chem. Phys., 2000, 113, 9978-9985. 